\title{
Causas de la pérdida de la confianza en la prensa y estrategias para su restablecimiento en un contexto de incertidumbre
}

\author{
Patricia María Nigro \\ Universidad Austral de la Argentina \\ pnigro@austral.edu.ar \\ https://orcid.org/0000-0002-2059-3179
}

\section{Causes for the loss of trust in the practices of the press and strategies for its restoration in a context of uncertainty}

\section{RESUMEN ABSTRACT}

A partir de la campaña electoral a la presidencia de EEUU en 2016, con el auge del concepto de "posverdad" y de noticias falsas, se produjo una crisis en la prensa que venía adaptándose con esfuerzo a la era digital. El objetivo de este artículo es describir cómo la posverdad y la proliferación de noticias falsas causaron una notable pérdida de credibilidad en las prácticas periodísticas de la prensa. Se proponen una clasificación de noticias falsas y algunas sugerencias muy concretas para su detección. La influencia viralizadora de las redes sociales encuentra a los periodistas poco capacitados para usar sus principios éticos básicos: chequear sus fuen-

tes y compararlas. La facilidad del posteo de información no verificada provoca el desarrollo de las organizaciones de chequeo de datos y la misma prensa, la academia y las redes sociales, intentan controlar la verdad de los hechos publicados. Se concluye que, entre otras estrategias, es urgente volver a enseñar conceptos básicos de ética periodística en las escuelas y facultades de periodismo para solucionar el problema de la confianza en las prácticas periodísticas.

PALABRAS CLAVE

Posverdad, Noticias falsas; Chequeo de datos, Periodismo, Aprendizaje del periodismo
Starting from the electoral campaign for the presidency of the USA in 2016, with the heyday of the concept of "posttruth" and fake news, the press, which had been adapting with effort to the digital age, suffered a crisis. The purpose of this paper is to describe how the post-truth concept and the proliferation of false news caused a notable loss of credibility in the journalistic practices. We offer different types of fake news and some specific strategies to detect them. The viralization by social media finds journalists poorly trained to use their basic ethical principles: check their sources and compare them. The easiness of unverified information's posts triggers the development of fact-checking organizations; and the press itself, the academy and social media, try to control the truth of the published facts. To conclude, among other strategies, it is of utter urgency to start teaching once again the basis of journalistic ethics in Journalism Schools in order to solve the trust issue in press practices.

\section{KEY WORKS}

Post-truth, Fake news, Fact-checking, Journalism, Journalism-learning contexto de incertidumbre. Hipertext.net, (17), 54-63. D0I:10.31009/hipertext.net.2018.117.05 


\section{Introducción}

Cuando el periodismo, la política y la academia, se encontraron desprevenidos ante la aparición de la posverdad, de los hechos alternativos, de las noticias falsas y de los chequeadores de datos, diferentes investigadores comenzaron a analizar, a tratar de entender la realidad nueva que sacudió-podríamos decir- el corazón de la práctica periodística: su credibilidad. Esta se basó siempre en la ética de sus profesionales y, ahora, el nuevo escenario obliga a replantearse, si los hechos son todavía sagrados o si su trabajo debe cambiar los estándares de calidad.

En distintos tiempos, el periodismo narrativo, el cívico, el digital y el de datos, provocaron crisis que llevaron a mejorar los productos periodísticos. Hoy, nuevamente, la profusión de noticias falsas causa el replanteo en el dictado de licenciaturas, de las diplomaturas, de los cursos y de las publicaciones.

Aunque siempre existieron noticias falsas, (pensemos en los libelos o en el periodismo amarillo), podemos afirmar que el cambio del contrato de lectura periodística (Verón, 1985) se inició en 2016 con tres hechos históricos: el triunfo de Donald Trump en las elecciones presidenciales en los Estados Unidos de América; el Brexit o la salida del Reino Unido de la Unión Europea y el NO a la paz del plebiscito por el pase a legalidad de las Fuerzas Armadas Revolucionarias de Colombia (las FARC). Sin embargo, esto fue solamente el inicio.

Desde entonces, se produjo y se sigue produciendo una copiosísima producción de artículos de investigación y de ensayos, de notas periodísticas, de entrevistas a expertos en Comunicación Social, a políticos, a miembros de organizaciones no gubernamentales y a los lectores de la prensa. Todos debían o deben decir algo al respecto ya que lo sucedido no era solo un cambio de soporte (como algunos consideran a la digitalización de la prensa): surgía un nuevo paradigma para definir los estándares de la calidad periodística. Esto fuerza tanto a una revisión de la ética de la actividad como a la de las prácticas cotidianas. Este nuevo paradigma interpela a distintos actores sociales y se dirige a la esencia de la democracia, tal como la conocíamos hasta hoy. Ante la caída de la imagen positiva de políticos y funcionarios, los que velaban por la verdad eran los periodistas. Pero ahora, si se ha perdido la confianza en la prensa, ¿quién o quiénes ocupan su lugar?

En verdad, el uso irresponsable de las redes sociales produjo una viralización de las noticias falsas. Buena parte del periodismo abandonó su premisa básica: chequear y contrastar fuentes de la información y se hizo eco de los sembradores de mentiras, de rumores, de teorías conspirativas, Toda esta caótica situación causó que se reprodujeran (aunque ya existían pero eran muy pocas y casi desconocidas) las organizaciones de fact-checking.

Este artículo es, desde lo metodológico, un ensayo descriptivo que se basa en el análisis de un corpus de documentos escritos y orales, referidos a la posverdad, a las noticias falsas, a las organizaciones de chequeo de datos, a la News Literacy y que se detiene en las causas de la pérdida de confianza en la prensa, a raíz del surgimiento de este nuevo paradigma. Y, pretende, entonces, hacer visible una nueva área de investigación en el periodismo. Intenta demostrar que, entre otras estrategias, es urgente volver a enseñar conceptos básicos de ética periodística en las escuelas y facultades para solucionar el problema de la confianza en las prácticas periodísticas.

\section{Desarrollo}

\subsection{Sobre la posverdad}

En 2016, el Oxford Dictionary eligió palabra del año a "posttruth" usada como adjetivo (post-truth politics). En 2017, la palabra entró en el Diccionario de la lengua española como sustantivo. Para Álex Grijelmo (2017), en nota del diario El País del 29 de junio, la posverdad refleja aquello que las personas sienten ante un estímulo, sus emociones respecto de una idea o de un líder, sus sensaciones subjetivas y esto prima en las decisiones que toman y resulta así más importante para ellos que la verdad misma.

Asimismo, se ha producido un cambio en el valor semántico del prefijo "post": desde 1992, hay usos en sentido tradicional (después de saber la verdad) pero, en 2004, aparece el primer libro con el sentido The post truth era de Ralph Keyes, que se le da en el concepto de posverdad.

Siguiendo con la idea, muchos autores consideran que la posverdad es una mentira (Berckemeyer, 2016; Molina, 2017; Torres, 2017). Una mentira que persuade, ya que apela a emociones o creencias y no a datos objetivos. Aristóteles (1999), hace 2500 años, en su Retórica, había llamado falacias a estas estrategias persuasivas (Nigro y Blaquier, 2014; Perelman y Olbrechts-Tyteca, 1989). En la posverdad, se repiten una y otra vez las falacias de apelación a la emoción (ad misericordiam), de ataque al otro y no a sus argumentos (ad hominem), de apelación a la tradición, la falacia estadística, la ambigüedad, la generalización, la simplificación, entre otras. ${ }^{1}$ Asimismo, la posverdad puede verse como un "hueco semántico" que discrimina la verdad revelada de la verdad sentida. (Amón, 2016)

Cuando el jefe de prensa del presidente Trump mintió a los periodistas acreditados en la Casa Blanca sobre cuánta gente había ido a su asunción, la directora de campaña, en una entrevista televisiva, insistió en que su colega no había mentido sino que había contado los "hechos alternativos" (alternative facts). Chuck Todd, el periodista que la entrevistaba, contestó: "Los hechos alternativos son mentiras" (Abramson, 2017; Graham, 2017). Así, surgía una nueva manera de nombrar la posverdad. Otros modos de llamar a estos hechos son: hechos adicionales, información alternativa, incompleta. Los hechos 
alternativos son la materia prima de la posverdad. Para Daniel Funke, del Poynter Institute (Funke, 2017), los hechos alternativos pueden ser verdaderos pero irrelevantes. Son mentira, siempre se usan para negar la realidad. El Poynter Institute propone no refutarlos, sino demostrar con pruebas la mentira que los sostiene.

Wiñazki prefiere el término "posmoralidad" al de posverdad por entender que encuadra más las múltiples tendencias que se están produciendo actualmente. Dice: "La posmoralidad es el espíritu de esta época, cuando la ética nos resulta indiferente" (2017, p.7).

El concepto de posverdad es útil, porque obliga a repensar qué es la verdad ${ }^{2}$ y qué es la mentira. En el campo filosófico, los límites son difusos. Sin embargo, el periodismo no es filosofía. En las redacciones, solía repetirse la frase: "Los hechos son sagrados, las opiniones son libres." Esto suponía que un periodista ético, profesional, debía contrastar y verificar bien sus fuentes, antes de publicar una noticia.

\subsection{Las noticias falsas}

La posverdad se establece cada día porque las redes sociales viralizan las noticias falsas ("fake news") (Nafria, 2017). Esta viralización se da de muchos modos y por distintos motivos:

- Es un fenómeno global.

- Trabaja sobre dos comportamientos humanos: reforzar creencias y negar lo que rechazamos previamente.

Se esparce rápidamente por las redes y por los filtros de los algoritmos.

Es un negocio internacional que da ganancias.

Se alimenta de la polarización y de los sesgos ideológicos.

Para un periodista, es simple retuitear o repostear lo que otro ya tuiteó o posteó, sin realizar verificación alguna. Es fácil modificar una foto, editar un video o producir ediciones erróneas de las entrevistas y que, de ese modo, se generen noticias falsas. Además, los usuarios de las redes también retuitean mensajes que concuerdan con su sistema de creencias, sus sentimientos, su ideología. Por esto, se habla de una "burbuja informativa" (Prego, 2016), en la que prevalecen tanto los algoritmos que comandan las redes sociales como los lectores, que pueden creer más a un amigo que periodista o investigador. Es cierto que siempre hubo noticias falsas. Amado (2017) sugiere, con humor inteligente, que las inventó Orson Wells en su transmisión de La guerra de los mundos del 30 de octubre de 1938.

La expresión noticia falsa, como señalamos, viene del inglés "fake news", en 2017 elegida, en inglés, palabra del año (Clases de Periodismo, 2017). En español, existe una palabra que significa exactamente lo mismo. En el Diccionario de la lengua española (2018), encontramos: "paparrucha". ${ }^{3}$

Además, a las noticias falsas, se suman los tuiteros falsos (los trolls) y los bots. Explica Fernández (2018): (Un troll es...) una cuenta en una red social (en general, Twitter) cuya generación de contenido es automatizada.

¿Qué es un troll? Alguien enfocado en acosar, criticar o antagonizar de manera provocadora y despectiva. Un bot (aféresis de robot) es un programa informático que efectúa automáticamente tareas repetitivas a través de Internet, cuya realización por parte de una persona sería imposible o muy tediosa.

La verificación es la esencia de la ética periodística. Se trata de identificar datos, revisar los nombres, contactar las fuentes, examinar las declaraciones, las estadísticas. Chequear consiste en determinar si una afirmación es verdadera o falsa, según la evidencia que la respalda.

Este tipo de verificación exhaustiva:

No se enseña de modo sistemático en las escuelas de periodismo.

Se relaciona con la objetividad y da prestigio a la profesión periodística.

- Consiste en investigar a las fuentes, contrastarlas, buscar testigos...

- Es lo que se hace ANTES de publicar.

La revista Time comenzó a practicarlo en 1923 (Silverman, 2018).

Algunos autores prefieren el nombre "desorden o trastornos de la información" en lugar de "noticias falsas". Es, entre otros, el caso de la Red Ética, perteneciente a la Fundación Nuevo Periodismo Iberoamericano (2017). Se puede describir esos trastornos de la información, de acuerdo con lo que propone la organización First Draft (Wardle, 2017): se distingue entre lo que es falso; lo que es falso e intenta hacer daño a otros; y lo que solo intenta hacer daño a otros. Son falsos los casos de noticias con errores contextuales o con información confusa o no verificada (en inglés, mis-information); son falsos con intención de dañar a otros (desinformación propiamente dicha) los casos de mentir sobre el contexto, manipular o fabricar contenidos y es "mala información", es decir, que solo tienen intención de dañar a otros, ciertas filtraciones de información, el discurso de odio y las amenazas.

A continuación, nombraremos algunas de las organizaciones periodísticas, de las redes sociales, de las universidades, que se están ocupando del chequeo de datos en las noticias publicadas a diario. Chequeado.com (2010) es un sitio de la Argentina, en línea desde octubre de 2010. Es el primero de 


\begin{tabular}{|l|l|l|}
\hline Niveles & Característica & Clases De Contenidos \\
\hline Verde & Neutral & $\begin{array}{l}\text { Propaganda: publicada por gobiernos u organizaciones. Puede ser beneficiosa o dañina. } \\
\text { Apela a la emoción. }\end{array}$ \\
\hline Amarillo & Peligro leve & $\begin{array}{l}\text { Títulos engañosos (clic baits): buscan la atención con sensacionalismo pero la noticia } \\
\text { trata de algo distinto. }\end{array}$ \\
\hline & $\begin{array}{l}\text { Contenido patrocinado: una publicidad con el aspecto de una noticia. Debe estar bien } \\
\text { aclarado el patrocinio, de lo contrario, se crea confusión en el público. }\end{array}$ \\
\hline Anaranjado & Peligro medio & $\begin{array}{l}\text { Sátiras: se realizan con ironía con fines humorísticos. Pueden confundir al lector no } \\
\text { atento. }\end{array}$ \\
\hline Rojo & Gran peligro & $\begin{array}{l}\text { Eibelos partidistas: son comentarios ideologizados fuertemente, que buscan persuadir } \\
\text { de cualquier modo. }\end{array}$ \\
\hline & $\begin{array}{l}\text { Teorías conspirativas: explican una realidad de modo de generar miedo o incertidum- } \\
\text { bre, no admiten refutaciones. }\end{array}$ \\
\hline & $\begin{array}{l}\text { Pseudociencia: propone curas milagrosas, miente sobre hechos comprobados, contra- } \\
\text { dice a los expertos. }\end{array}$ \\
\hline & \begin{tabular}{l} 
Desinformación: combina hechos con mentiras, hace atribuciones falsas. \\
\hline
\end{tabular} & $\begin{array}{l}\text { Falsedades: son totalmente falsas, publicadas para confundir, motivadas por dinero, } \\
\text { ideología o influencia. }\end{array}$ \\
\hline
\end{tabular}

\section{Tabla1. Elaboración propia a partir European Association for Viewers Interests.}

América latina. Exportó su método de verificación a Colombia, Brasil, Uruguay, El Salvador, México y Perú. Asimismo, hay numerosas organizaciones pertenecientes a medios en inglés, a diferentes universidades, a ONGs y existe una asociación que nuclea a todas: Polifact (2018). En Facebook, la Red Ética de la Fundación del Nuevo Periodismo Iberoamericano tiene una página llamada "Esta noticia es falsa" en la que se informa, se discute y se trabaja activamente sobre el tema.

Posverdad, noticias falsas, hechos alternativos, desinformación: para recuperar la confianza perdida, se necesitan estrategias. Describiremos muchas estrategias que ya existen $y$, permanentemente, aparecen nuevas. Es necesario probar y ser perseverantes, porque encontrar la verdad es muy difícil.

No todas las noticias que parecen falsas lo son. En la Tabla 1 comentamos la clasificación de la European Association for Viewers Interests (2018) (eavi.eu) que las clasifica con colores según su nivel de peligrosidad, o sea, su capacidad de dañar. Es importante poder distinguir a qué tipo de noticia nos estamos enfrentando para luego neutralizar su influencia negativa, si la tuviere.

Las organizaciones de fact-checking suelen tipificar las noticias falsas de distintos modos y proponer métodos para verificar los datos y comunicarlos al público (Echevarría, 2017). Elegiremos una clasificación de noticias falsas que consideramos completa y clara. La propone la organización First Draft (Wardle, 2017):

Seguidamente, se brindan algunas estrategias básicas para detectar noticias falsas. Están tomadas de la Federación Internacional de Asociaciones de Bibliotecarios y Bibliotecas (IFLA,
2017).

Revisar quién es la fuente: preguntarse: ¿quién es el que manda el mensaje?, ¿qué sabemos ciertamente de esa persona u organización?, ¿qué dice en "Sobre nosotros" o "About us" en el sitio, si lo fuere?, ¿qué objetivos persiguen los autores?

Averiguar quién es el autor: buscar de dónde proviene esa persona (si es que es real), qué dijo antes y qué dice hoy, indagar mucho antes de tratar el tema como un hecho.

Revisar las fechas: muchas veces los textos son antiguos (esto pasa especialmente con fotos tomadas en otro momento o lugar). La fecha es importante. ¿Es un dato nuevo o es una repetición manipulada de algo viejo?

Reflexionar sobre la posición del autor en ese tema: fijarse si lo que cuenta el mensaje falso confirma ideas previas, prejuicios y lleva por eso a querer compartirlo.

Leer connotativamente: preguntarse: ¿qué implica o supone este mensaje? ¿Qué bien o mal puede causar? En definitiva, se trata de usar el pensamiento crítico.

Buscar las fuentes que el texto refiere: si el texto cita a un autor, comprobar si eso es cierto; si da una estadística, ver de dónde se tomó y de cuándo es; si tiene enlaces, cliquear para ver adónde llevan.

Pensar si no es una ironía o broma: existen periódicos y revistas satíricas, que usan el humor para relajar el ambiente o para criticar pero no dejan de ser una broma. 


\begin{tabular}{|l|l|}
\hline Tipos & Explicación \\
\hline Sátira o parodia & $\begin{array}{l}\text { Siempre existieron publicaciones, en las que se tomaba con ironía la verdad para tratar de modo indi- } \\
\text { recto ciertos temas. Estas no son noticias falsas pero, si el lector no está muy informado, puede creer } \\
\text { que el chiste o la ironía es verdadero. }\end{array}$ \\
\hline Contenido engañoso & $\begin{array}{l}\text { Se usa cierta información (que puede ser verdadera o no) pero se la malinterpreta para dañar a } \\
\text { alguien. }\end{array}$ \\
\hline Contenido impostor & $\begin{array}{l}\text { Una frase cobra sentido en un determinado contexto comunicativo. Si el que habla es un experto y } \\
\text { opina sobre el tema de su conocimiento, es válido. Pero, si el que habla o escribe, no conoce el tema y } \\
\text { toma frases de otra persona y las manipula y atribuye falsamente, eso constituye contenido impos- } \\
\text { tor. }\end{array}$ \\
\hline Contenido fabricado & $\begin{array}{l}\text { Se produce cuando hubo la intención de dañary, a causa del avance tecnológico, pueden ser mensa- } \\
\text { jes muy verosímiles pero nunca verdaderos. }\end{array}$ \\
\hline Conexión falsa & $\begin{array}{l}\text { La mayoría de las personas lee los titulares. En Twitter, muchos tuits tienen enlaces que nadie abre. } \\
\text { Los usuarios los diseminan basándose solo en el título. }\end{array}$ \\
\hline Contexto falso & $\begin{array}{l}\text { El sentido de una expresión se juega en un contexto o situación comunicativa dada. Lo que se llama } \\
\text { sus condiciones de enunciación. Cambiar la situación comunicativa es cambiar el sentido del mensaje } \\
\text { (Hymes, 1974). }\end{array}$ \\
\hline Contenido manipulado & $\begin{array}{l}\text { Fotos, gráficos o videos que pueden alterarse con las posibilidades tecnológicas actuales (Marzal } \\
\text { Felici y Casero Ripollés, 2017; Pellicer, 2017). }\end{array}$ \\
\hline
\end{tabular}

Tabla 2. Elaboración propia a partir de Claire Wardle, de First Draft (Wardle, 2017).

- Preguntar a los que saben: usar las redes sociales para preguntar a los expertos en el tema.4

A continuación, se ofrecen otras estrategias más concretas, en cuanto al tipo de medio de comunicación:

En las redes sociales, es necesario preguntarse:

- ¿Es el contenido original?

- ¿Quién tomó la foto, el video o la declaración?

- ¿Cuándo se tomó ese contenido?

¿Dónde? (Wardle, 2017)

Cuando los mensajes públicos contienen imágenes y videos, se puede recurrir a:

Encontrar la fuente original: la cámara o el móvil.

Observar con atención: ropa, paisaje, idioma, vehículos, clima.

Búsqueda reversa de imágenes: Google Search o Tin Eye.

regex.info/exif.cgi o InVid: información básica de la foto o el video.

En los sitios web, se pueden seguir las siguientes indicaciones:

Buscar el dominio. Domain Big Data.

Usar Google Analytics + AdSense o SpyonWeb.com

Se buscan URL.

http://bit.ly/verificationtoolsandtips (Silverman, 2018)

\section{3 ¿Por qué creemos en las noticias falsas?}

La razón humana se fundamenta, en gran parte, en la sociabilidad. El hombre es, para Aristóteles, zoón logón (animal racional o animal que habla)- lógos, en griego, significa razón y lenguaje a la vez. El hombre, para Aristóteles, es también, zoón politikón (animal que vive en sociedad). Todo esto significa que, para el filósofo griego, nuestra capacidad de juicio estaba condicionada naturalmente por lo que piensa o cree la comunidad a la que pertenecemos.

El 27 de febrero de 2017, en The New Yorker, Kolbert revisó investigaciones de diferentes universidades que demostraban que la razón y la evidencia no cambian nuestra opinión. Algunos de los fenómenos que se han comprobado ya son:

El "sesgo de confirmación": es una característica del intelecto humano que tiende a buscar la información que fortalece sus creencias y debilita las opuestas. Se encuentran fallas en el razonamiento ajeno pero no en el propio.

La "ilusión de la profundidad explicativa": es un fenómeno por el cual se cree que se sabe más de lo que en verdad se sabe.

Los "sentimientos fuertes": no surgen de una racionalidad profunda. Las neurociencias demuestran un aumento de la dopamina, cuando la gente encuentra que alguna de sus creencias es confirmada. Para el médico argentino, López Rosetti (2017, p.11): "no somos seres racionales sino seres emocionales que razonan". Por eso, en las redes, se opina lo mismo que los propios seguidores o se sigue a los que opinan lo mismo que uno mismo. Algunos llaman a este fenómeno vivir en una "burbuja informativa" (Prego, 2016), porque lo que se hace no es escuchar al que piensa 
distinto sino apoyarse en los que piensan igual que uno. $Y$ esto, indirectamente, multiplica las noticias falsas.

Las "respuestas complejas y correctas": no suelen interesar al público. En cambio, las respuestas simples pero incorrectas son más cómodas y se acomodan a la habitual pereza intelectual de los seres humanos.

Todos estos fenómenos se relacionan con lo que el psicólogo social León Festinger (1975) llamó hace tiempo "disonancia cognitiva": un estado de tensión y conflicto interno que se nota cuando la realidad choca con las creencias. Muchas veces se elige manipular la verdad para mantenerlas a salvo.

Desde la Psicología, Torres (2017) en "Posverdad (mentira emotiva): definición y ejemplos", dice:

"La posverdad es un contexto en el que no importan si los hechos son verdaderos o falsos. Platón, en el Mito de la Caverna, planteó que la verdad es independiente de nuestras opiniones." De este modo, la objetividad importa mucho menos que el modo en que lo que se afirma encaja en nuestro sistema de creencias.

Por otra parte, Nietzche en "Verdad y mentira en sentido extramoral" (2010) sostiene que la verdad es la mentira que la sociedad tolera y que se convierte así en una no-mentira. Para el filósofo, en el discurso público, todas las verdades son creencias ficcionales.

Sobre el tema de la "burbuja informativa", se debe tener en cuenta el aporte de Pariser en su libro El filtro burbuja (2017). El autor explica cómo afecta el uso de los algoritmos la vida cotidiana y cómo crea una "burbuja que filtra" (traducción correcta del título del libro en inglés) lo que llega a nosotros. Sobre la base de los algoritmos, (cada "Me gusta" que se cliquea), las redes sociales y las plataformas como Google deciden qué interesa y lo envían en los newsfeed que se reciben. Así, no se accede a diferentes realidades o modos de pensar. Sin decidirlo, se vive rodeado por los que piensan del mismo modo.

\subsection{La pérdida de la confianza en el periodismo}

Para tratar el tema de la crisis de credibilidad en el periodismo, recurriremos a Boczkowski y Lewin (2018), quienes identifican una actitud de "egocentrismo mediático" en los periodistas, es decir, la suposición del valor del periodismo en la sociedad y de una resistencia a explorar nuevas relaciones. Se han minimizado, según estos autores, los desafíos competitivos y se dejaron pasar las iniciativas tecnológicas. Asimismo, muchos periodistas vieron la innovación como amenaza, en lugar de como oportunidad. El periodismo tradicional está, de esta manera, cada vez más desconectado de su público.

Como antiguos gatekeepers, muchos periodistas siguen atados a las rutinas periodísticas y al prestigio profesional. Sin embargo, el contexto en que se vive actualmente es total- mente otro. A partir del surgimiento de los blogs, cualquiera puede escribir. Además, las redes sociales muestran cómo funciona la comunicación pública. Hay una nueva ecología de la información y todo esto provoca la pérdida de confianza en la prensa. La alternativa que proponen los investigadores para superar la crisis es la de un periodismo relacional, porque las noticias son una empresa en red. Acercarse a su público, escuchar sus necesidades, mostrar cómo trabajan los periodistas, reconocer su falibilidad, dar prioridad a las noticias locales, son algunas de las propuestas.

Así también, muchos periodistas son meros repetidores de las palabras de sus fuentes a las que poco cuestionan. Núñez Ladevéze llamó a esta práctica utilizar, sin reflexionar, "la jerga del portavoz", es decir, usar los "modos léxicos y expresivos que distinguen a los productores de información cuando se transmiten a través del lenguaje y del estilo periodístico" $(1993,143)$.

Entonces, para referirnos más en concreto, a la pérdida de credibilidad en el periodismo, se planteará el camino inverso. ¿Qué factores producen que confiemos en la información que brinda la prensa? Estos son:

Prestigio adquirido: hay muchos medios que, con el paso del tiempo, con la trayectoria de los periodistas que firman sus notas, han adquirido ya un prestigio que el público reconoce. Es más difícil que se dude de lo que dice un medio prestigioso de uno que no lo sea.

Frecuencia: aquí se trata de la frecuencia con que un tema es tratado y seguido por el medio. Muchas veces, una noticia relativamente importante solo aparece una vez y luego se pierde para siempre o la continuidad que se le da es mínima. Usualmente, el público quiere saber cómo terminó la historia o en qué punto está.

Familiaridad: cuando un medio de comunicación, toma y desarrolla temas que tocan de cerca a su público, es más fácil que se crea en ellos. La cercanía de la noticia es importante para las audiencias.

Rectificaciones: es importante que los medios reconozcan que no son infalibles. En este nuevo contexto comunicativo, ya no son los "perros guardianes" o "gatekeepers". La gente se informa mediante muchas vías y, si un medio se equivoca, debe rectificar el error. Paradójicamente, un medio que reconoce su error es más creíble que el que no lo hace.

\section{Códigos de ética.}

Buenas prácticas profesionales.

Presencia de los ombudsman o defensores del público en los medios.

Transparencia en los métodos y los motivos empleados. 
Ejercicio de la humildad.

Creación de equipos de redes sociales en los medios. Cada medio de comunicación debería tener periodistas en esos equipos. Profesionales que conozcan el campo trabajando en conjunto con los expertos en redes sociales. (Silverman, 2018).

Enseñanza del discernimiento, de la lectura crítica de los mensajes públicos (News Literacy o Alfabetización en Noticias). Este es un problema de todos los ciudadanos pero especialmente de periodistas y de formadores de periodistas, del sistema educativo. Se verá en el punto 2.5 .

Cerramos este apartado recordando algunos puntos del "Decálogo del periodista" del escritor y periodista argentino, Tomás Eloy Martínez (2005):

El único patrimonio del periodista es su buen nombre. Cada vez que se firma un artículo insuficiente o infiel a la propia conciencia, se pierde parte de ese patrimonio, o todo.

No hay que escribir una sola palabra de la que no se esté seguro, ni dar una sola información de la que no se tenga certeza plena.

Hay que trabajar con los archivos siempre a la mano, verificando cada dato y estableciendo con claridad el sentido de cada palabra que se escribe.

Hay que evitar el riesgo de servir como vehículo a los intereses de grupos públicos o privados. Un periodista que publica todos los boletines de prensa que le dan, sin verificarlos, debería cambiar de profesión y dedicarse a ser mensajero.

Recordar siempre que el periodismo es, ante todo, un acto de servicio. Es ponerse en el lugar del otro, comprender lo otro. $Y$, a veces, ser otro.

\subsection{La “News Literacy” o Alfabetización en noticias}

Mucho tiempo atrás, se llamaba a la News Literacy: lectura crítica del diario. El foco estaba puesto en distinguir entre hechos y opiniones. Ahora, el contexto es mucho más complejo. Por este motivo, hay que resignificar esta tarea, básicamente educativa. Si no se puede saber con certeza si lo que dice la prensa que es un hecho ES realmente un hecho, es imperioso aprender a verificar las fuentes, a confrontar los "datos" que se publican con la realidad en que se vive.

Como ejemplos de organizaciones prestigiosas que trabajan estos temas, podemos nombrar el Poynter Institute (2017) que ofrece un certificado de especialización en línea sobre la Newsliteracy que implica la aprobación de cuatro cursos: Fuentes, verificación y credibilidad; News Literacy l; Exactitud y verificación en la era digital y Entendiendo los Medios: procesos y principios.

The Knight Center for Journalism in the Americas (2017) dictó también, en noviembre de ese año, un curso en línea en español sobre fact-checking y periodismo de datos, a cargo de Laura Zommer, presidenta de Chequeado.com En abril de 2018, se ofreció otro curso en línea, en inglés, sobre verificación y confianza que estuvo a cargo del editor de Buzzfeed en Canadá, Craig Silverman.

Muchos sitios de Internet enseñan cómo chequear datos en la escuela, primaria o media, o en la universidad. El más completo hasta ahora es The News Literacy Project (2018). Otros ejemplos son:

Checkology. Organización que propone este tipo de aprendizajes desde el aula virtual. https://checkology.org

Slate. Página que ofrece recursos para docentes y para padres. https://amp.slate.com/articles/technology/ future_tense/2017/11/in_the_age_of_fake_news_it_s_ never_too_early_to_teach_kids_media_literacy.html

Facebook First Draft. Facebook ofrece herramientas para detectar noticias falsas. https:// newsroom.fb.com/news/2017/04/a-new-educational-tool-against-misinformation

- Think tank new media. Página que brinda explicaciones muy claras para los docentes. http:// thinktankmedia.mx/detector-de-noticias-falsas

Según pase el tiempo y avancen las investigaciones y la toma de conciencia del problema, más sitios surgirán y mejorará su calidad.

En este trabajo, se señala como un punto clave para la recuperación de la confianza en la prensa el papel de la universidad que debe dejar de ser centrípeta y prestar atención a con qué competencias llegan a las aulas académicas sus estudiantes. Esto supone abrirse al resto del sistema educativo para capacitar a los docentes de los niveles medios y primarios. Lo mismo vale para las organizaciones de medios que brindan cursos sobre redes sociales, verificación de datos y News Literacy.

En una ponencia de 2017, sostuvimos con el Dr. Fernando Rivas: "...le cabe al mundo de la prensa y a sus instituciones, como a las de educación, ocuparse por este tema en el sentido de acrecentar el desarrollo del pensamiento crítico, por medio del dominio de competencias y habilidades específicas y crecientes" (2017, p.24).

Los mismos medios han de colaborar en la educación de los ciudadanos ofreciendo servicios informativos de alta calidad (Sanchez Díez, 2017). La autora señala que han de colaborar con las escuelas o facultades de periodismo. Los estudiantes 
deben estar presentes en redacciones por todo su entusiasmo, por su conocimiento de la vida digital y por todo lo que ellos pueden aprender de los periodistas profesionales.

Algunas propuestas pedagógicas actuales y que merecen destacarse son: @Orson1938, alfabetismo educativo transmediático y alfabetización transmedia @Trans_Literacy (ambas direcciones son de Twitter).

\section{Conclusiones}

Para concluir este análisis de las causas de la pérdida de la confianza o credibilidad en la prensa, solamente se realizarán dos reflexiones consideradas como las más importantes.

En primer lugar, la necesidad de que se desarrolle una nueva instancia de investigación en estudios sobre el periodismo de modo tal de que se recupere poco a poco la credibilidad perdida. En este trabajo, se revisaron las causas complejas que deberían ser profundizadas para mejorar la calidad de las producciones periodísticas (Universidad de Externado de Colombia, 2017; Cebrián, 2018). Sobre este tema, Cebrián dice:

Si queremos consolidar la democracia y garantizar el futuro de las instituciones contra las posverdades y la manipulación informativa, los medios de referencia deben recuperar su papel central en el debate político, en la Red y fuera de ella.

También Orihuela (2018) reafirma la misma idea:

A pesar de que la desinformación no es un tema nuevo en el ámbito de los estudios sobre Comunicación, hay que asumir que la transformación del escenario de la información que han producido Internet y las redes sociales confiere una nueva dimensión a los fenómenos de manipulación informativa. Hay que estudiar y educar acerca de la naturaleza, mecanismos e impactos sociales, políticos y económicos de los trastornos de la información.

Las causas de la desconfianza conforman justamente los núcleos de la nueva área de investigación y se enumerarán ahora en orden: Posverdad (concepto, los hechos alternativos, falacias, formación de creencias); Noticias falsas (tipos, modos de reconocimiento, organizaciones de fact-checking y sus funciones); News Literacy (diferentes propuestas para enseñar a chequear datos y a desarrollar el pensamiento crítico en los jóvenes ciudadanos); Prensa y Redes (relaciones, efectos de la viralización, modos de usar las redes por parte de los periodistas, creación de equipos de redes sociales en los medios (Elizabeth, en ADEPA, 2017); Restablecimiento de la confianza en el periodismo (propuestas, cursos, redefinición de la calidad y de la ética periodística).
En segundo lugar, la pérdida de confianza en las publicaciones periodísticas, fenómeno que se ha profundizado notablemente. Una gran mayoría del público no se informa por los llamados medios tradicionales. Existen importantes trabajos empíricos que, cuantitativa y cualitativamente, evalúan cómo esa confianza va decreciendo y la realidad no ha hecho más que empeorar (Boczkowski, 2017; Rosen, 2017; Ramírez, 2018; Williams, 2018). Rosen sugiere abrir las prácticas periodísticas a la participación de los lectores, en una artículo de María Ramírez para el Nieman Lab se enumeran cinco estrategias para recuperar la confianza perdida y, finalmente, Williams advierte del peligro de esa pérdida de confianza para la vida democrática, en la cual el periodismo había sido siempre históricamente la voz de los que no tenían acceso a la información provista por los gobiernos. Asimismo, este trabajo propone una vuelta a la ética periodística y la necesidad de un retorno a la verificación y a la comparación de las fuentes, práctica básica de periodista profesional, y a la enseñanza de estos núcleos o contenidos en las escuelas o facultades de Periodismo.

\section{Notas a final de página}

1. Falacia es cualquier razonamiento indebido (es decir, no construido correctamente) pero convincente. Las falacias pueden ser intencionales o no serlo (Nigro y Blaquier, 2014, p.15).

2. Aquí, por cuestiones de espacio, definiremos la verdad como la concordancia entre lo dicho y la realidad y no profundizamos en la complejidad de este concepto.

3 De páparo.

- a. f. coloq. Noticia falsa y desatinada de un suceso, esparcida entre el vulgo.

- b. f. coloq. Tontería, estupidez, cosa insustancial y desatinada.

- c f. León. Masa blanda, como la del barro.

4. Cfr. Boczcowski, P. y Aruguete, N. (2017) y Orihuela, J. (2018).

\section{Referencias}

Abramson, J. (23 de enero de 2017). Los hechos alternativos son solo mentiras, no importa lo que sostenga Kellyanne Conway. The Guardian. Recuperado de https://www.theguardian.com/commentisfree/2017/jan/23/kellyanne-conway-alternative-facts-lies

ADEPA (2017). Equipos de redes sociales: el arma secreta contra la desinformación. ADEPA. Recuperado de http://adepa.org.ar/equipos-de-redes-sociales-el-arma-secreta-contra-la-desinformacion

Amado, A. (2017). Con ustedes Orson Wells, el inventor de las fake news. Wetoker.com. Recuperado de http://wetoker.com/orson-welles-el-inventor-de-las-fake-news

Amón, R. (16 de noviembre de 2016). Posverdad: palabra del año. El Pais.com. Recuperado de https://cdn.ampproject.org/c/ internacional.elpais.com/internacional/2016/11/16/actualidad/1479316268_308549.amp.html

Aristóteles. (1999). Retórica. (Edición del texto con aparato crítico, traducción, prólogo y notas por Antonio Tovar). Madrid: Centro de Estudios Constitucionales, $4^{\text {a }}$ edición. 
Berckemeyer, F. (2016). La mentira de la posverdad. Uno: pensamiento independiente para tomadores de decisiones, (27), 26-27.

Boczkowski, P. (2017). Las noticias falsas y el futuro del periodismo. La postverdad. Revista anfibia. Recuperado de http://www.revistaanfibia.com/ensayo/la-postverdad

Boczcowski, P. y Aruguete, N. (30 de marzo de 2017). Fake news: qué es lo nuevo y qué se puede hacer para enfrentarlas. (Conferencia) Universidad Torcuato Di Tella Buenos Aires. Recuperado de http://www.utdt.edu/ver_evento_agenda.php?id_evento_agenda=3601धid_item_menu=440

Boczkowski, P. y Lewin, S. (2018). Medios. Cómo recuperar lo que teníamos. Revista Anfibia. Recuperado de http://www.revistaanfibia. com/ensayo/medios-recuperar-lo-teniamos

Cebrián, J.L. (15 de febrero de 2018). La prensa libre, frente a la posverdad. La Nación. Recuperado de https://www.lanacion.com. ar/2109186-la-prensa-libre-frente-a-la-posverdad

Clases de Periodismo (2 de noviembre de 2017). Fake news (noticias falsas) es la palabra del año en 2017. Clases de Periodismo. Recuperado de http://www.clasesdeperiodismo.com/2017/11/02/fakenews-noticias-falsas-es-la-palabra-del-ano-en-2017

Echevarría, B. (17 de enero de 2017). Más 'fast-checking' contra la posverdad. Cuadernos de periodistas. Recuperado de http://www. cuadernosdeperiodistas.com/mas-fact-checking-la-posverdad

EAVI (2018). Fake news and online disinformation. EAVI Media Literacy for Citizenship. Recuperado de https://eavi.eu/european-commissions-public-consultation-on-fake-news-and-online-disinformation

Fernández, P. M. (13 de noviembre de 2017). El mundo secreto de los bots y los trols... y cómo esos 'ejércitos' influyen en la política. Chequeado. Recuperado de http://www.chequeado.com/investigacion/el-mundo-secreto-de-los-bots-y-los-trolls-y-como-esosejercitos-influyen-en-la-politica/?utm_content=buffer8ba36\&utm _ medium=social\&utm_source=twitter.com\&utm_campaign=buffer

Festinger, L. (1975). Teoría de la disonancia cognoscitiva. Madrid: Instituto de Estudios Políticos.

Funke, D. (31 de octubre de 2017). First Draft offers 35 recommendations to counter misinformation. Poynter. Recuperado de https:// www.poynter.org/news/first-draft-report-offers-35-recommendations-counter-misinformation

Graham, D. A. (22 de enero de 2017). Los hechos alternativos: las innecesarias mentiras de la administración Trump. The Atlantic. Recuperado de https://www.theatlantic.com/politics/ archive/2017/01/the-pointless-needless-lies-of-the-trump-administration/514061

Grijelmo, A. (29 de junio de 2017). La posverdad salta al diccionario. El Pais.com. Recuperado de http://cultura.elpais.com/ cultura/2017/06/29/actualidad/1498755138_986075.html?id_ externo_rsoc=TW_CC

Hymes, D. (1974). Foundations of Sociolinguistics: An Ethnographic Approach. Philadelphia: University of Pennsylvania.

IFLA. (20 de agosto de 2017). Cómo las bibliotecas pueden ayudar a conseguir soluciones reales para las noticias falsas. IFLA Noticias. Recuperado de https://www.ifla.org/ES/node/11631

Keyes, R. (2004). The post-truth era. Dishonesty and deception in contemporary life. New York: St. Martin Press.

Knight Center. (2017). Knight Center offers new free course in Spanish, "Fact-checking and data journalism." Register now!.[jour- nalism in the americas Blog]. Recuperado de https://knightcenter. utexas.edu/blog/00-18880-knight-center-offers-new-free-coursespanish-fact-checking-and-data-journalism-registe

Kolbert, E. (27 febrero de 2017). Why Facts Don't Change Our Minds: New discoveries about the human mind show the limitations of reason. The New Yorker Recuperado de https://www.newyorker.com/ magazine/2017/02/27/why-facts-dont-change-our-minds

López Rosetti, D. (2017). Emoción y sentimientos. No somos seres racionales, somos seres emocionales que razonan. Buenos Aires: Planeta.

Martínez, T. E. (10 de septiembre de 2005). Los titulares de mañana, La Nación. Recuperado de https://www.lanacion.com. ar/737489-los-titulares-de-manana

Marzal Felici, J. y Casero Ripollés, A. (2017). El fotoperiodismo en la era de la posverdad. adComunica. Revista Científica de Estrategias, Tendencias e Innovación en Comunicación, (13), 11-17.

Nafria, I. (2017). Las pautas de The New York Times sobre el uso de las redes sociales por parte de sus periodistas (traducción al español). [Blog ismaelnafria.com]. Recuperado de http://www.ismaelnafria. com/2017/10/20/las-pautas-de-the-new-york-times-sobre-el-usode-las-redes-sociales-por-parte-de-sus-periodistas-traduccion-alespanol

Nietzche, F. (2010). Sobre verdad y mentira en el sentido extramoral y otros fragmentos de filosofía del conocimiento. Madrid, España: Tecnos.

Nigro, P. y Blaquier, A. (2014). Desnudando el discurso político. Falacias, políticos y periodistas. Buenos Aires, Argentina: Biblos.

Nigro, P. y Rivas Inostroza, F. (2017). Estrategias democráticas para enfrentar las consecuencias de la posverdad en el periodismo político. XIII Congreso Nacional de Ciencia Política. "La política en entredicho. Volatilidad global, desigualdades persistentes y gobernabilidad democrática", Buenos Aires, Sociedad Argentina de Análisis Político, 8811-8842.

Nuñez Ladevéze, L. (1993). Teoría y práctica de construcción del texto. Investigación sobre gramaticalidad, coherencia y transparencia de la elocución. Barcelona: Ariel.

Orihuela, J. (22 de enero de 2018). Trastornos de la información (mejor que fake news). Breve guía de autodefensa frente a la desinformación. Medium. Recuperado de https://medium.com/@jlori/trastornosde-la-informaci\%C3\%B3n-mejor-que-fake-news-7a9ae44f7cc7

Oxford Dictionaries (2016). Posverdad, la palabra del año 2016. Recuperado de https://en.oxforddictionaries.com/word-of-the-year/ word-of-the-year-2016

Pariser, E. (2017). El filtro burbuja. Cómo la red decide lo que leemos y lo que pensamos. Barcelona: Taurus.

Pellicer, M. (2017). Visual Trumpery: los gráficos que cuentan mentiras. [Blog Miquel Pellicer]. Recuperado de https://miquelpellicer.com/2017/06/visual-trumpery-los-graficos-para-contar-mentiras

Perelman, C. y Olbrechts-Tyteca, L. (1989). Tratado de la argumentación. La Nueva Retórica. Madrid, España: Gredos.

Poynter Institute (2017). Poynter News Literacy Certificate. Poynter. News University. Recuperado de https://www.newsu.org/poynter-news-literacy-certificate?utm_source=newsletter\&utm_ medium=email\&utm_campaign=digest\&utm_content=Litcert

Prego, V. (2016). Burbujas informativas. Uno: pensamiento independiente para tomadores de decisiones, (27), 20-21. Recuperado de 
https://www.revista-uno.com/numero-27/burbujas-informativas

Ramírez, M. (3 de enero de 2018). "Five tools to rebuild trust in media". Recuperado de http://niemanreports.org/articles/five-tools-to-rebuild-trust-in-media

Real Academia Española. (2017). Entrada "paparrucha". Recuperado de http://dle.rae.es/?id=RlvnOag

Red Ética. (7 de noviembre de 2017). Reporte ofrece 35 recomendaciones para combatir la desinformación. Red Ética. Programa Ética Periodística. Recuperado de http://www.fnpi.org/es/etica-segura/ reporte-ofrece-35-recomendaciones-para-combatir-la-desinformacion

Red Ética (2018). Esta noticia es falsa. [Blog Perfil Facebook]. Recuperado de https://www.facebook.com/search/top/?q=esta\%20 noticia\%20es\%20falsa

Rosen, J. (31 de diciembre de 2017). Show your work: The new terms for trust in journalism. Press Think. Recuperado de http://pressthink. org/2017/12/show-work-new-terms-trust-journalism

Sánchez Díez, M. (28 de julio de 2016). Por qué es importante que los medios colaboremos con escuelas de periodismo. Medium. Recuperado de https://medium.com/univision-beta/m\%C3\%A1sall\%C3\%A1-de-las-pr\%C3\%A1cticas-por-qu\%C3\%A9-es-importanteque-los-medios-colaboremos-con-escuelas-de-f71a3e77e058

Silverman, C. (2018). Trust and Verification in the age of misinformation. Journalism Courses. Recuperado de https://journalismcourses. org/TV0312.html

Torres, A. (2017). Posverdad (mentira emotiva): definición y ejemplos. Psicología y mente. Recuperado de https://psicologiaymente.net/ social/posverdad

Universidad Externado de Colombia. (2017). Los retos del periodismo en la era de la 'posverdad'. Recuperado de https://www.uexternado. edu.co/comunicacion-social-periodismo/los-retos-del-periodismo-la-la-posverdad

Verón, E. (1985). El análisis del 'Contrato de Lectura', un nuevo método para los estudios de posicionamiento de los soportes de los media. En "Les Medias: Experiences, recherches actuelles, aplications". París: IREP.

Wardle, C. (14 de marzo de 2017). Noticias falsas. Es complicado. First Draft. Recuperado de https://es.firstdraftnews.org/2017/03/14/noticias-falsas-es-complicado

Williams, B. (29 de enero de 2018). As the threat of 'fake news' to democracy grows, public trust in the media wavers. Sunlight Foun- dation. Recuperado de https://sunlightfoundation.com/2018/01/29/ as-the-threat-of-fake-news-to-democracy-grows-public-trust-inthe-media-wavers

Wiñazki, M. (2017). La posmoralidad. Reflexiones éticas para la esperanza. Buenos Aires: Sudamericana.

\section{Portales web}

Chequeado. La verificación del discurso público. Recuperado de https://chequeado.com

Polifact. Fact-checkin US Politic. Recuperado de http://www.politifact.com

The News Literacy Project. Recuperado de_http://www.thenewsliteracyproject.org

\section{CV}

Patricia María Nigro. Doctora en Comunicación Social por la Universidad Austral de la Argentina. Investigadora y docente en la Facultad de Comunicación y Coordinadora del Área de Educación a Distancia de la Escuela de Posgrados de Comunicación de la misma casa de estudios. Licenciada en Organización y Gestión Educativa, posgrado en Ciencias del Lenguaje y Profesora de Letras, es autora de ocho libros académicos y de casi 100 artículos científicos y de divulgación. Profesora Titular II de Teoría y Práctica de la Lengua 1 y 2 , se especializa en lenguaje periodístico y político, argumentación y en el campo de la interdisciplina entre la Comunicación y la Educación. Se desempeña, también, como directora de tesis doctorales y de maestría. Forma parte, como evaluadora de proyectos de investigación y de postulación para cargos docentes universitarios, del Programa "Más Valor" del Consejo Nacional de Investigaciones Científicas y Técnicas (CONICET). https://austral.academia.edu/PatriciaNigro

https://seminariosnigro.wordpress.com

https://twitter.com/nigropatricia
Observatorio de Cibermedios

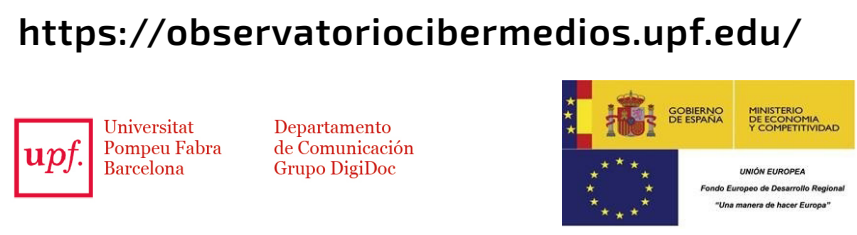

El Observatorio de Cibermedios es una producción del Grupo de Investigación en Documentación Digital y Comunicación Interactiva (DigiDoc) del Departamento de Comunicación de la Universitat Pompeu Fabra.

El Observatorio de Cibermedios (OCM) forma parte del proyecto del Plan Nacional "Creación y contenido interactivo en la comunicación de información audiovisual: audiencias, diseño, sistemas y formatos". CS02015-64955-C4-2-R (MINECO/ FEDER), Ministerio de Economía y Competitividad (España). 